Portland State University

PDXScholar

$9-1-2018$

\title{
Internal Gravity Waves and Meso/Submesoscale Currents in the Ocean Anticipating High-Resolution Observations from the SWOT Swath Altimeter Mission
}

\author{
Edward D. Zaron \\ Portland State University, ezaron@pdx.edu \\ Cesar B. Rocha \\ University of California - San Diego
}

Follow this and additional works at: https://pdxscholar.library.pdx.edu/cengin_fac

Part of the Civil and Environmental Engineering Commons

Let us know how access to this document benefits you.

\section{Citation Details}

Zaron, E. D., \& Rocha, C. B. (2018). Internal Gravity Waves and Meso/Submesoscale Currents in the Ocean: Anticipating High-Resolution Observations from the SWOT Swath Altimeter Mission. Bulletin of the American Meteorological Society, 99(9), ES155-ES157. https://doi.org/10.1175/BAMS-D-18-0133.1

This Post-Print is brought to you for free and open access. It has been accepted for inclusion in Civil and Environmental Engineering Faculty Publications and Presentations by an authorized administrator of PDXScholar. Please contact us if we can make this document more accessible: pdxscholar@pdx.edu. 


\section{Meeting Summary:}

2. Internal Gravity Waves and Meso/Sub-mesoscale Currents in the Ocean anticipating high-resolution observations from the Surface Water \& Ocean

\section{Topography (SWOT) swath altimeter mission*}

Portland State University, Portland, Oregon

${ }_{9}^{*}$ Corresponding author address: Department of Civil and Environmental Engineering, Portland

10 State University, PO Box 751, Portland, OR 97207.

11 E-mail: ezaron@pdx.edu

\footnotetext{
${ }^{*}$ E. D. Zaron and C. B. Rocha. Meeting summary: Internal gravity waves and meso/submesoscale currents in the ocean: Anticipating highresolution observations from the SWOT swath altimeter mission. Bulletin of the American Meteorological Society, 99, 2018.

http://dx.doi.org/10.1175/BAMS-D-18-0133.1
} 


\begin{abstract}
${ }_{12}$ Meeting Title: Interactions Between Internal Gravity Waves and Meso/Sub-

${ }_{13}$ mesoscale Currents in the Ocean

${ }_{14}$ What: An international group of 45 scientists met to discuss observational

15 evidence, theoretical descriptions, and consequences of interactions between

${ }_{16}$ high-frequency internal gravity waves and low-frequency meso- and sub-

17 mesoscale currents in the ocean.

${ }_{18}$ When: February 10-11, 2018

${ }_{19}$ Where: Portland, Oregon
\end{abstract}


Satellite altimetry, an observational technique that uses radar to measure water surface elevation from satellites orbiting the Earth, has provided a near-global view of ocean variability and revolutionized oceanography in a manner similar to the role played by geostationary satellites in atmospheric science. Data from a constellation of satellite altimeters, beginning with TOPEX/Poseidon in 1992, have led to insights concerning ocean predictability and mesoscale dynamics (?), observations of global sea level rise and variability (?), and a renaissance in tidal studies (?). The meeting held February 10-11, 2018, "Interactions Between Internal Gravity Waves and Meso/Submesoscale Currents in the Ocean," convened a group of oceanographers to discuss topics likely to be similarly invigorated in the near-future by the Surface Water \& Ocean Topography swath altimeter mission, anticipated for launch in 2021.

Near-inertial waves and internal tides are the dominant modes of high-frequency internal variability in the ocean, and they scatter into a broad-band inertia-gravity wave spectrum. These high-frequency waves interact with low-frequency motions associated with "balanced" turbulence (including geostrophic mesoscale eddies and sub-mesoscale fronts and vortices with finite Rossby number). Theoretical and numerical studies of the last decade have demonstrated the importance of these interactions for wave dispersion and energy transfers in the $1 \mathrm{~km}-100 \mathrm{~km}$ scale range, as well as for their effects on the spatial variability of mixing and routes to dissipation. Recent studies have highlighted the potential impacts of these wave-turbulence interactions on not only high-resolution in-situ observations but also high-resolution satellite observations. The workshop sought to review what is known about internal wave-balanced interactions, identify questions that still need to be addressed, and consider how to meet these new challenges in the context of both fieldwork and numerical modeling. 


\section{Highlights}

Several interesting themes emerged from the meeting. The main observational challenge to studying interactions between internal waves and meso-/submesoscale phenomena is the wide range of space and time scales that must be resolved. An ongoing study in the Western Pacific, near the Luzon Strait, is using multiple gliders to observe the upper kilometer of the ocean at horizontal scales from a few kilometers - the width of topographic features where internal tides are generated and the size of submesoscale currents-to hundreds of kilometers, approaching the scales of internal tides and geostrophic mesoscale eddies. Researchers are finding that it is possible to identify baroclinic tides, which vary significantly over the time it takes for a glider to complete its vertical profile, and distinguish them from the slowly-evolving meso- and submescale fields. Observations of surface currents at $1 \mathrm{~km}-100 \mathrm{~km}$ scales were also reported. These are being collected by high-frequency radar stations along coastlines of North America, Europe, and East Asia, and analysis of these is providing information about the kinetic energy spectrum of surface currents. Innovative remote sensing techniques for measuring small-scale roughness were also presented which show promise for estimating divergence and rate-of-strain of surface currents.

A number of theoretical studies were reviewed that-in contrast to observational studiesisolate the physical mechanisms of interactions. One study, based on an asymptotic model that coupled near-inertial waves coupled with quasi-geostrophic flow, predicts a transfer of energy from the geostrophic flow to the waves related to the reduction of wave length scales by advection and refraction. Another study showed how wave dissipation can catalyze a net conversion of otherwise reversible energy exchange from a geostrophic flow to near-inertial waves. Also, high resolution, idealized Boussinesq numerical simulations were reported in which energy transfers were decomposed in terms of deformation shear production and buoyancy fluxes; this enabled an 
assessment of the role of wind-driven internal waves in damping mesoscale eddies. Interpretation of even these simplified studies is complicated by the three-dimensional nature of the interactions, and the apparent mixture of direct energy exchanges versus scale-dependent energy cascades.

The meeting featured results from an increasing number of studies with realistic numerical models that include both high-frequency forcing from tides, winds, or both, and low-frequency forcing from winds and buoyancy fluxes. Reported simulations have horizontal resolutions down to hundreds of meters and upper-ocean vertical resolution of a few meters, thus resolving geostrophic eddies, ageostrophic fronts, and internal waves. Presentations described how the models are being used to investigate the origin of the internal-wave continuum, and to design the SWOT calibration/validation field campaign. Interesting comparisons of HYCOM, MITgcm, and ROMS simulations show disagreements in internal-wave energy across models, unrelated to grid resolution, which are currently under investigation by the modeling community. Comparisons with observations highlight the overall realism of global internal-tide-resolving models, but they are also finding order-of-magnitude local discrepancies that deserve further investigation. Increasing resolution of the models presents challenges for analysis of flow interactions, and there is renewed interest in the relationships between kinematic versus dynamical flow decompositions divergent/rotational versus wave/balanced versus high-/low-frequency - and their usefulness for interpreting both models and observations.

\section{Outcomes}

The workshop provided the opportunities to exchange information between communities which do not frequently interact. Historically, studies of ocean mesoscale and submesoscale turbulence have not been closely tied to studies of inertia-gravity internal waves. Studies of large-scale ocean turbulence have been dominated by an emphasis on potential vorticity dynamics, while studies of 
inertia-gravity waves emphasize linear wave dispersion, ray tracing, and wave action conservation. The fields have generally emphasized different observational techniques aligned with the time and spatial scales of interest.

Planning for the SWOT mission is motivating more interactions between these communities, because of the unique potential of the mission to observe inertia-gravity waves, mesoscale, and submesoscale processes expressed in the topography of the ocean surface. Learning from these observations will be a challenge because the 21-day repeat sampling of the mission will alias high-frequency inertia-gravity waves and rapidly-evolving submesoscale structures. Nonetheless, specialists from diverse areas recognize the potential significance of making sustained, near-global measurements of sea-surface height across the $1 \mathrm{~km}$ to $100 \mathrm{~km}$ range of scales.

Outcomes of the meeting include new collaborations between modelers and observationalists, such as plans to investigate the degree to which predictable baroclinic tidal variability can be mapped and removed from observations. There are also plans to revise the SWOT white papers to explicitly highlight linkages between mesoscale, submesoscale, and inertia-gravity wave phenomena and dynamics. This should provide a forum for communicating with the broader oceanographic community in order to plan for and maximize the SWOT mission's science results. 


\section{References}

Fu, L., D. Chelton, P.-Y. LeTraon, and R. Morrow, 2010: Eddy dynamics from satellite altimetry. Oceanography, 23 (4), 1425, doi:10.5670/oceanog.2010.02.

Ray, R. D., and G. D. Egbert, 2017: Chapter 13: Tides and satellite altimetry. Satellite Altimetry over Oceans and Land Surfaces, D. Stammer, and A. Cazenave, Eds., CRC Press, 427-458.

Watson, C. S., N. J. White, J. A. Church, M. A. King, R. J. Burgette, and B. Legresy, 2015: Unabated global mean sea-level rise over the satellite altimeter era. Nature Climate Change, 5, 565-568. 
${ }_{112}$ LIST OF FIGURES 


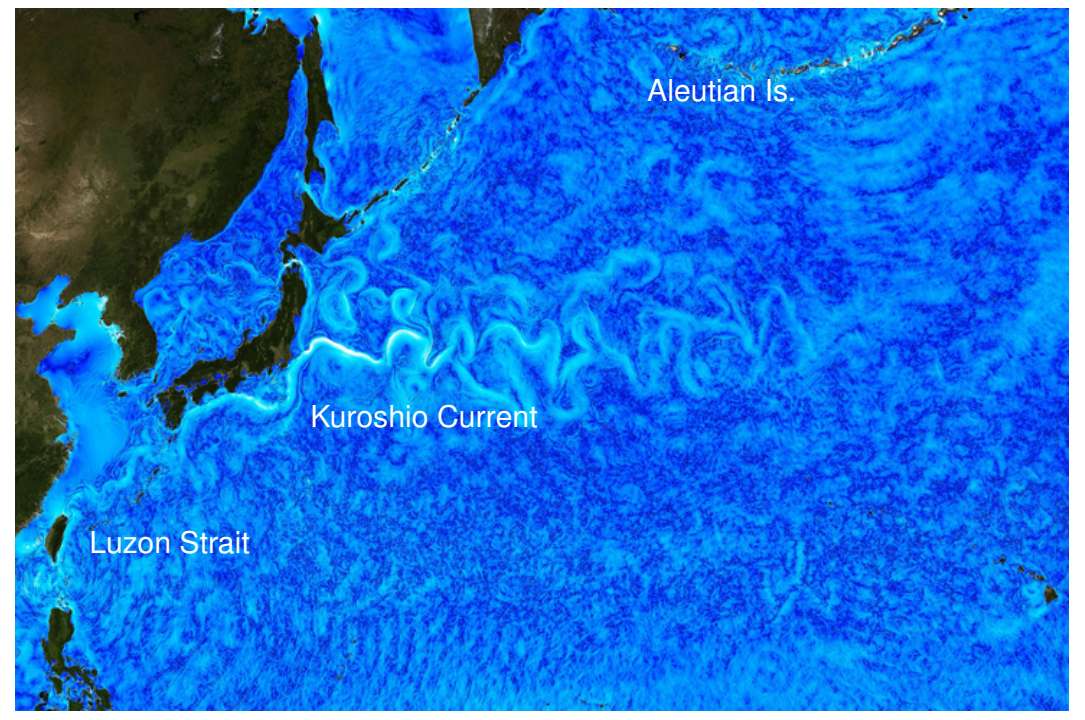

FIG. 1. This snapshot of surface current speed in the Western North Pacific from a $(1 / 48)^{\circ}$-resolution MITgcm simulation illustrates familiar features such as the Kuroshio Current and its mesoscale meanders and rings. Also visible are wave patterns caused by internal tides emanating from Luzon Strait and the Aleutians Islands, and ubiquitous sub-mesoscale currents. High-resolution simulations such as this are being used to study interactions between internal gravity waves and meso/sub-mesoscale currents, as discussed at the workshop (image provided by Dimitris Menemenlis). 